\title{
Control and guide mechanisms under the university network public opinion "micro-era" Background
}

\author{
Chen Hongqi ${ }^{1, \text { a }}$, Li Zhigang ${ }^{2, b}$ \\ ${ }^{1}$ Jiangxi Science \& Technology Normal University, Nanchang, Jiangxi, 330013, P.R. China \\ a375828970@qq.com, ${ }^{\text {b }}$ lizg98@126.com
}

Keywords: Micro era, University network public opinion, Control and guidance mechanism

\begin{abstract}
With the rapid development of network technology in contemporary society, microblogging has gradually integrated into people's daily lives, providing people exchanges and new tools of communication, but also brought new challenges and opportunities for the university network public opinion control. This paper describes the current status of public opinion, the university proposed new strategies to control and guide public opinion.
\end{abstract}

\section{Introduction}

With the rapid development of the Internet, the emergence of microblogging, forums, micro-letters and other networking tools for students to bring a broader sources of information, the network public opinion has gradually become a new topic of major campus management, and its mode of transmission shown in Figure 1 FIG. College students are the largest users, but also the network of public opinion the most major impact strength, even the campus public opinion can be transformed into public opinion, inspire social public opinion. To this end, the university should continue to strengthen the network of social management, the traditional work with modern information combined with public opinion, to establish a leading technology, new areas of integration of resources, new channels, and constantly promote development and progress in the University.

\section{College Network control and guide public opinion Situation}

The current network of colleges and universities, public opinion reflects mainly university students attitudes and awareness of Internet events, its content diversified trend. Internet public opinion is mainly involved students' daily life and learning, can help students keep abreast of hot issues at home and abroad; formed exhibits rapid, in relatively closed campus, dissemination of information is easy to form bias, influence public opinion, and provoke emergencies; its main exhibit centralized, Students with a strong convergence, more susceptible to the surrounding environment and unable to respond to emergencies in a timely manner.

Universities of public opinion to guide the work of the control to be further strengthened, first guide public opinion ranks relatively weak regulatory agencies are not clear, resulting in not unified management, while the professional staff is poor public opinion, can not be accurately monitored, analyzed, and guide and so on. Second, public opinion is also guiding mechanism is not perfect, the university did not release audit mechanism established public opinion, nor set up contingency plans to prepare mature and can not handle unexpected network events, it is difficult to control public opinion. Finally, public opinion guidance technology is relatively backward, there is a certain blindness traditional artificial means, can not meet the current network development process of society.

\section{Principles university network control and guidance of public opinion}

Directional principle. Directionality of the university network is the basic principle to be followed by public opinion, it should be stressed that public opinion in the right direction for development, so that the socialist modernization drive before train outstanding talent. Students are in 
the formative years of the world, life and values, good or bad network information will directly affect students' thinking and behavior. Therefore, universities should be for students to guide public opinion, and poor control of public information, not blind obedience, not gullible, so rational treatment function and value of the network of public opinion, so that it can guide the students towards the energetically favorable direction.

Timeliness principle. Development of the university network public opinion should also follow the principles of timeliness, timely grasp point in time, timely, timely, public information dynamically reflect the network. Timeliness mainly refers to when the hot events at home and abroad, the school may be the first time to react, and to evaluate and analyze, understand the real situation of events, quick to explain, guide the basic trend of public opinion. Timeliness mainly refers to universities should be at the right time to guide public opinion, public opinion is determined according to developments in the release time. Rapid spread easily lead to the recipient information online media Nishajuxia, network information are also communicators, and only choose the best time to guide public opinion, before they can successfully handle emergencies, mitigate the impact of public opinion.

The principle of unity. Universities, public opinion guidance control process should always adhere to the principle of unity, control and guide public opinion is a very complex project, content rich, diverse, and therefore the boot process must be consistent both within and outside the unified command. In case of emergency, the university should expand emergency work decisively to ease the process of development of the situation, to avoid further spread. Outgoing different answers if the same event, originally a simple situation can become complex and cumbersome, therefore, we must speak with one voice when released information, all public opinion management coordination and cooperation, so as to regulate the thinking and behavior of college students, promoting physical and mental health development of.

Targeted principle. Universities, public opinion is mainly aimed at staff and students of the school, and therefore should be the fundamental interests of the teachers and students of departure, research network concerns of teachers and students, will guarantee student life, learning bad information from outside influence as the main task, to make possible normal university teaching activities to collect public opinion, to ensure the completeness and accuracy of public opinion, to ensure against damage. Under the premise of network media diversity, exchange and communication of information is equal to interact online, only with full respect for the wishes of users, strengthen communication concept, we can really get to understand users, thereby reducing the incidence of public opinion crises.

\section{"Micro-era" under the background of the university network control public opinion to guide Countermeasures}

Internet public opinion related to the development prospects of universities, decided to physical and mental health of college students, only the law of development of scientific understanding of network public opinion, good control and guidance work, we can achieve effective management of public opinion.

Construction Microarchitecture, strengthen public opinion monitoring system. Compared with other network platform, universities microblogging then have greater public advantage, as a new network media, microblogging more attention groups, make full use of the advantages of microblogging, public opinion can quickly seize the initiative. Colleges and universities should first establish the university's official microblogging, and strengthen supervision, establish interest and knowledge of combining authoritative information platform, to grasp the network public opinion, to achieve double-effect one thought and technology. The person responsible, personal publishing, supervised, do the collection and analysis of information on the work of public opinion can be published for the first time the event occurred, mitigate the negative impact of public opinion, the timely processing of public opinion should realize microblogging crisis followed by the formation of public opinion monitoring organization team outbreak. Finally, we should cultivate a group of 
opinion leaders, the use of positive accuracy celebrity microblogging help information, to seize the initiative on public opinion should give full play to the positive initiative of college students, college students achieve self-management and self-education, and with opinion leaders appeal and appeal, to ensure proper dissemination of campus public opinion.

Grasp the micro dynamics, build public opinion Survey Office. In recent years, college students in the non-normal deaths, accidents, food poisoning and extreme political events at home and abroad and other issues comments frequently occur in the face of emergencies, universities only use microblogging platform to guide public opinion can only be a positive development. On the one hand, public opinion when faced with urgent cases, the relevant universities should be responsible for the timely introduction of public opinion contingency plans for the case to start a detailed investigation, tracing the sources of information, analysis of public opinion after the spread of effect size, and the first time a significant impact on reported cases upper management, to take the necessary means to deal with the positive response towards clarify the truth in the shortest possible time, the maximum possible eliminate the negative impact. On the other hand, the university should pay attention to positive publicity effect of public opinion, according to the site information to restore the true face of the event, the use of positive authoritative information repel malicious rumors. Meanwhile, sources on the network and low credibility of the information is unclear, universities should make full use of the role of spiritual leaders, strengthen positive publicity, and promptly remove bad information, the students calm panic, questioning, resentment and other emotions, truly maintenance Harmonious University and society stable.

Create micro effect, adhere to the ideological and practical combination. First, in the event of public opinion subsided Network, universities should be established to assess public opinion crisis management system, emergency countermeasures to respond timely to reflect public opinion control process outstanding issues, summed up the experience to guide public opinion, warning, increased from a fundamental major colleges and universities to control public opinion, the ability to boot. Secondly, the university should choose the right public opinion events, deep thoughts on college students education, positive transfer positive energy. Only in-depth analysis of the whole story truth emergencies verify critical information before they can withstand adverse events to enhance students' ability to identify and eliminate bad rumors. Finally, it should realize the double combination of management and service, public opinion staff Universities should always adhere to the ideological and practical combination of management philosophy, and actively support the economic difficulties, learning difficulties and student employment difficulties, public transparency appraised awards, student party as well as employment issues, improve information feedback mechanism, so that it can relieve the crisis of public opinion, public opinion, to ensure the safety of colleges and universities.

\section{Conclusion}

Universities often ideological and political education for students through the network, while taking advantage of the mainstream thinking of ideas to guide students to strengthen the control of public opinion to guide the work of universities is to promote awareness of an important part of students' promotion. Practical work, the university administration of public opinion through appropriate ways for students to network eliminating A puzzled, to guide students' healthy growth. College Network public opinion guidance and control needs to be further research and discussion, so that it can really create positive network environment for college students.

This paper is a research project of Humanities and social science research project in jiangxi province colleges and universities (NO. MKS1450).

\section{References}

[1] Y.Y. Zhou, fees Guoqiang. Ideological and Political Education of College Students Research microblogging vision. Ideological and theoretical education, 2011 (09). 
[2] Liu Zhijun network management and guiding public opinion, propaganda and ideological work in colleges and universities in the. School Party and ideological education, 2011 (22).

[3] The main experience of foreign network management and guidance of public opinion and the Enlightenment [3] Xuerui Han to China. CPC Fujian Provincial Committee Party School of 2012 (09).

[4] Yinpei Pei network public opinion analysis system Big Data era. Radio and television technology, 2013 (07). 